\section{A Longitudinal Study of Perceived Health during Pregnancy}

\author{
Antecedents and Outcomes
}

\section{ALINA RODRIGUEZ \& GUNILLA BOHLIN \\ Department of Psychology}

GUNILLA LINDMARK

Department of Obstetrics and Gynaecology,

Uppsala University, Sweden

a 1 in a r odrig u e z (phd, Uppsala University) is currently Research Fellow at the Department of Psychology, Uppsala University and Assistant Professor at Mälardalen University.

g u n il l a boh 1 in (phd, Uppsala University) is currently Professor of Developmental Psychology at the Department of Psychology, Uppsala University.

g u n il 1 a 1 in d mark (md, phd, Uppsala University) is currently Professor and Head of International Maternal and Reproductive Health at the Department of Women and Child Health, Uppsala University.

a ckn ow 1 edge men $\mathrm{t} s$. This research was funded by a grant from the Swedish Council for Planning and Coordination of Research and by the Foundation Lars Hiertas Minne. Thanks go to Drs Dag Sörbom and David Shapiro for their helpful comments.

c o mpe $t$ ing in t er est $\mathrm{s}$ : None declared.

a d d r e ss. Correspondence should be directed to:

a 1 in a r odrig u e z, Uppsala University, Department of Psychology, Box 1225, SE 75142 Uppsala, Sweden. [Tel. 4618471 7980;

Fax: 461847121 23; email: Alina.Rodriguez@psyk.uu.se]
Journal of Health Psychology Copyright (C) 1999 SAGE Publications London, Thousand Oaks and New Delhi, [1359-1053(199904)4:2]

Vol 4(2) 129-147; 007485

\section{Abstract}

Perceived health was studied longitudinally in a sample of 364 nulliparous women.

Psychosocial, contextual, and biomedical factors were taken into account to predict medically relevant versus benign symptoms which were then used to predict perceived health over time. The results of structural equation modeling showed that pregnancy adjustment and medically relevant symptoms which were affected by social support, perceived stress, and negative affect predicted later perceived health. The outcomes of perceived health were examined during the third trimester in terms of medical care utilization and emergency room visits. Perceived health solely accounted for medical care utilization, while emergency room visits were accounted by medical care utilization and perceived stress.

\section{Keywords}

self-rated health, symptoms, health-care utilization, pregnancy adjustment, psychosocial factors, health 
interest in perceived health (also referred to as self-rated health) has been growing exponentially within the last decade primarily because it has been found repeatedly to be a powerful predictor of mortality and morbidity even after controlling for variables related to health (for a review, see Idler \& Benyamini, 1997). These results have been replicated in a variety of populations including the elderly (Idler \& Kasl, 1991), the middle-aged (Moller, Kristensen, \& Hollnagel, 1996), and in national cohorts (e.g. Gold, Franks, \& Erickson, 1996). Idler and Benyamini (1997) recommend that future research should focus on special populations. We consider perceived health among pregnant women because pregnancy is a major understudied health event. Health concerns are salient for women during pregnancy. Pregnant women ranked information concerning the health of the fetus and their own health as the number 1 and 2 reasons for attending prenatal care (Rodriguez \& Bohlin, 1998).

Researchers have been in agreement for some time that perceived health is the individual's interpretation of his/her health which not only takes physical health into account, but also encompasses a psychosocial component (Kaplan \& Camacho, 1983; Maddox \& Douglas, 1973; Tessler \& Mechanic, 1978). Some of the psychosocial factors that have been associated with perceived health include distress among the elderly (Markides \& Lee, 1990), and perceived stress among adolescent girls (De Maio-Esteves, 1990). A recent study (Radanov, Schwarz, \& Frost, 1997) failed to find an association between negative affect among arthritic patients and their perceived future health status.

Because perceived health represents in part physical health, individuals may use symptoms as a sign of their perceived health status. Indeed, somatic change initiates a process in which individuals judge whether or not the change represents a symptom of an illness (Leventhal, Diefenbach, \& Leventhal, 1992). Cross-sectionally, symptoms have been found to be strongly associated with perceived health status in medical outpatients (Barsky, Cleary, \& Klerman, 1992) and with the perceived severity of one's cancer (Heidrich, Forsthoff \& Ward, 1994). There is prospective evidence from clinical trials in patient populations indicating that after symptoms are alleviated, perceived health improves
(Lukacs, Leplege, Thibault, \& Jardin, 1996; Nicholl et al., 1992).

However, the role of symptoms as a moderator of perceived health has not been systematically studied. Research has been limited in several ways. First, only a few community studies have included symptom reports (see Idler \& Benyamini, 1997). Second, the effect of symptoms may be difficult to discern in community samples because the illnesses that individuals experience vary considerably, and consequently so do their symptoms. Third and most importantly, there has been no attempt to discriminate medically relevant from benign symptoms (i.e. symptoms that do not necessarily indicate a medical problem). This distinction is particularly important when studying pregnancy because women experience a wide range of symptoms (Rodriguez, Lindmark, \& Bohlin, 1998) during the course of pregnancy, some of which are likely to indicate threats to the mother or fetus (Hunter, 1989) whereas others pose discomfort but are not hazardous in themselves (Bracken, Enkin, Campbell, \& Chalmers, 1989).

Like perceived health, reports of somatic symptoms seem to encompass both a biological and a psychological component (Pennebaker, 1982). Besides reflecting internal biological states (Diefenbach, Leventhal, Leventhal, \& Patrick-Miller, 1996), reports of symptoms have been found to be associated with negative affect retrospectively (Larsen, 1992) among young adults and prospectively (Leventhal, Hansell, Diefenbach, Leventhal, \& Glass, 1996) among elderly people. Although negative affect has not been linked to actual illness (Watson \& Pennebaker, 1989), more recent evidence shows an indirect association to illness (Van Eck, Berkhof, Nicolson \& Sulon, 1996) and to susceptibility to infection (Cohen, Tyrrell, \& Smith, 1993). Taken together, the evidence indicates that negative affect may both inflate symptom reports due to a response bias and it may affect disease severity which in turn affects symptom reports.

Hostility is predictive of mortality and physical symptoms (Miller, Markides, Chiriboga, \& Ray, 1995; Miller, Smith, Turner, Guijarro, \& Hallet, 1996) in general populations. Hostility has been neglected in studies of pregnant women; however, there are some data indicating 
that the trait hostility may be linked to pregnancy outcome and medically relevant symptoms during pregnancy (Omer, Elizur, Barnea, Friedlander, \& Palti, 1986). Perceived stress among adults has been associated with illness severity and related symptoms (Cohen et al., 1993) as well as to symptoms not related to pathology (Cohen \& Williamson, 1991). Perceived stress has also been linked to pregnancy outcomes (Paarlberg, Vingerhoets, Passchier, Dekker, \& Van Geijn, 1995; Wadhwa, Sandman, Porto, Dunkel-Schetter, \& Garite, 1993). Social support is an important psychosocial variable that has been associated with mortality in adults (Shumaker \& Hill, 1991). Social support has been coupled to favorable outcomes during pregnancy (Collins, Dunkel-Schetter, Lobel, \& Scrimshaw, 1993; Oakley, Hickey, Rajan, \& Rigby, 1996) and to symptoms (Zimmermann-Tansella, Bertagni, Siani, \& Micciolo, 1994). In sum, negative affect, hostility, perceived stress, and low social support are associated with illness and corresponding symptoms. Furthermore, negative affect and perceived stress have also been related to a bias to overreport symptoms. Consequently, we can expect to find that negative affect, hostility, perceived stress, and social support will predict medically relevant symptoms, and that negative affect and perceived stress will also predict benign symptoms.

Mortality, and to a lesser extent morbidity, have hitherto been the major endpoints of research concerning perceived health. Although there are a number of potential health threats during pregnancy for both the mother and the developing fetus, both enjoy low mortality rates in Sweden (Hogberg, Innala, \& Sandström, 1994). Therefore, it is more appropriate to examine medical care utilization as an endpoint of perceived health, instead of mortality. Medical care utilization has practical consequences for the individual in terms of health outcomes and for society in terms of medical care costs which represent a large portion of the gross national product in developed nations. Moreover, there is current international debate regarding the number of prenatal visits required to provide adequate screening (Alexander \& Kotelchuck, 1996). All things being equal, does perceived health have an impact on seeking medical care? This question is particularly important for women undergoing their first pregnancy, because they are confronted with a novel experience involving numerous physical changes. It is likely that the way women perceive their health during pregnancy and the degree of medical care they seek will depend on the symptoms they experience.

\section{Present study}

The purpose of this study was to identify the antecedents and examine the consequences of perceived health during pregnancy. Our aim was to develop a multifactorial model in which we use psychosocial and contextual factors to predict symptoms (medically relevant as well as benign) which are used in turn to predict perceived health longitudinally. In this way we may identify the direct and indirect pathways leading to perceived health. The inclusion of contextual variables has been recommended by previous researchers (Lederman, 1995; Stewart, 1996). We consider pregnancy adjustment because it has been found to have an impact on health awareness (Rodriguez, Bohlin, \& Lindmark, in press), pregnancy complications (Chalmers, 1983), and reported symptoms (Lederman, 1995). Furthermore, we examine medical care utilization, an important consequence of perceived health. As Figure 1 shows, we expect that medically relevant symptoms at week 28 will be affected by first-trimester perceived stress, social support, negative affect, and hostility, because these psychosocial factors have been previously associated with health outcomes and related symptoms. Given earlier research findings, we anticipate that benign symptoms will be predicted by negative affect, perceived stress, and pregnancy adjustment. We also expect that benign symptoms will be affected by medically relevant symptoms because the latter may be salient for women and may increase the likelihood that they monitor other symptoms. Perceived stress and both types of symptoms at week 28 are, in turn, used to predict perceived health during week 32 . Because perceived health has been found to be stable (Rodin \& McAvay, 1992), we predict that perceived health at the onset of the pregnancy will have an effect on later perceived health (week 32).

Given our longitudinal design, we can examine the possibility of a reciprocal effect of 


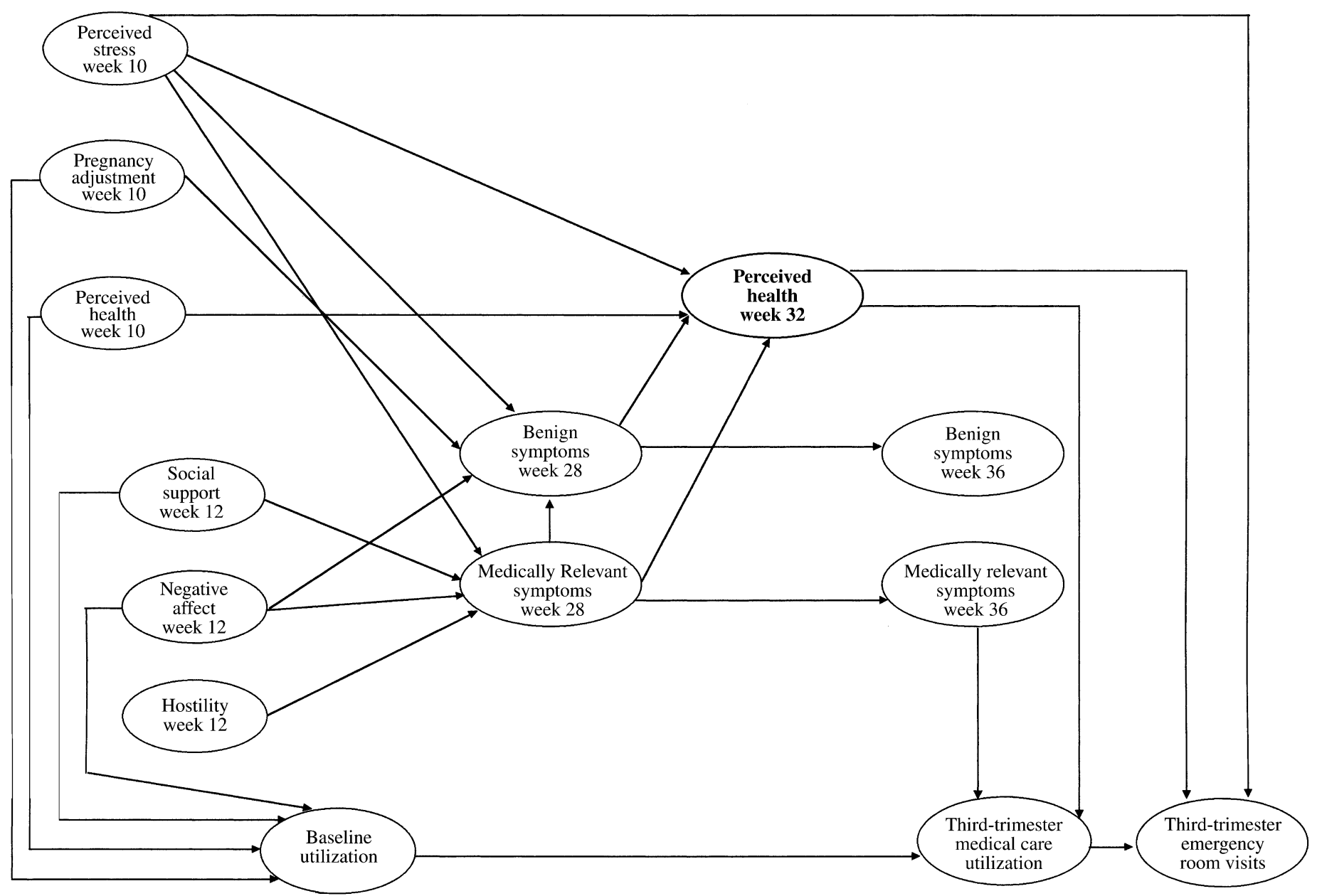

Figure 1. Hypothesized model. 
perceived health and symptom reports. In other words, perceived health may also have an effect on symptom reports, such that perceiving one's health as poor may lead to increased sensitivity and hence greater symptom reporting. To examine the proximal versus distal effect of perceived health on symptom reports, we assessed symptoms again at week 36 . In this way, we may assess whether perceived health predicts subsequent symptoms, and if so whether the time lag is of importance. We also have the opportunity to check for the stability of symptom reports over time.

Health care utilization has been linked to negative affect (Cohen \& Rodriguez, 1995) and perceived stress (Cohen \& Williamson,1991). There is some evidence suggesting that social support and pregnancy adjustment are positively associated with participation in prenatal health care (Giblin, Poland, \& Ager, 1990). Inasmuch as health care utilization contributes to the perception of health, studies partial out the effect of utilization when studying perceived health (e.g. Idler \& Kasl, 1991; Mossey \& Shapiro, 1982; Rodin \& McAvay, 1992). We believe that it is important to examine the association in the opposite direction, that is poor perceived health leading to greater health care utilization. Lack of prenatal health care has long been considered a risk factor (Goodwin, Dunne, \& Thomas, 1969) and its initiation is recommended to occur as early as possible (Alexander \& Kotelchuck, 1996). In sum, we predict that uptake of prenatal care during the first half of pregnancy will be influenced by negative affect, pregnancy adjustment, social support, and perceived health at week 10 .

Seeking medical care during the last trimester (above and beyond routine prenatal health care) may consist of visiting an obstetrician or the emergency room. We separate these two measures of utilization because they seem to be conceptually different behaviors. A visit to an obstetrician entails an appointment whereas emergency room visits are made on the spur of the moment and thus are likely to involve different variables from a planned visit. We predict that perceived health at week 32 , medical symptoms during the end of pregnancy, and prior health care utilization will explain medical care utilization in terms of visits to an obstetrician. We propose that emergency room visits will be predicted by stress, perceived health, and concurrent medical care utilization. Long-term stress has been found to be an independent predictor of care-seeking behaviors in a sample ranging from middle-aged to elderly adults (Cameron, Leventhal, \& Leventhal, 1995).

A number of studies use self-reports of illness (e.g. Rodin \& McAvay, 1992) as a measure of health from which to predict perceived health. Self-reports may be confounding. It is difficult to discern whether perceived health changed as a result of a diagnosis or if the medical practitioner's remarks were interpreted in a biased manner. In other words, it may be possible that people who perceive their health as poor interpret remarks as confirming poor health status. In the present study, we statistically controlled for the medical practitioners' diagnoses and risk factors. We controlled for factors that would affect the amount of prenatal care that participants utilized (twins, gestational diabetes, number of hospitalized days, current disorders, and gestational age) as well as medical conditions (threatened miscarriage, suspected fetal growth deviation, and gestational complications such as anaemia, proteinuria, and high blood pressure) that would affect utilization and perceived health. These data were retrieved from the medical charts. We also controlled for socioeconomic status (SES), in terms of education and income, because it has been found to be related to differences in health status (Gudmundsson, Bjorgvinsdottir, Molin, Gunnarsson, \& Marsal, 1997; Taylor, Repetti, \& Seeman, 1997).

\section{Method}

\section{Participants}

This study is a subset of a larger longitudinal investigation concerning pregnancy and health in which pregnant women were followed from their first prenatal visit to postpartum using a repeated-measures design. Participation was limited to Swedish nulliparous women in order to limit variance due to parity and culture. On average, the women were 27 years of age $(\mathrm{SD}=$ 4), had completed 4 years of secondary education, and had an annual income that corresponds to the Swedish national average for women aged between 20 and 34 years (Swedish Census, 
1993). Most of the women (91 percent) lived with the baby's father. Standard demographic data, e.g. age and civil status, were obtained from the medical charts. Of the 525 women who were eligible, 91 percent agreed to participate and so we obtained at least one measure from 476 women. The effective sample size used for analyzing the model was 364 after we made pairwise deletions for missing data.

\section{Setting}

Participants were recruited from five prenatal health care centers in Uppsala County, Sweden. Midwives solicited the participants during their first scheduled appointment, at approximately 10 weeks of gestation. Prenatal health care is offered free of charge to all Swedish residents and all pregnant women take advantage of this service, since private alternatives are not widespread (Åberg \& Lindmark, 1992). The women in this sample attended routine prenatal health care which means that midwives had the primary responsibility for monitoring their pregnancies. The recommended routine prenatal program at the time of the study was 10 visits to the midwife (this sample: $M=10.27, \mathrm{SD}=2.51$ ), one visit to an obstetrician during the first trimester, and an optional visit to the obstetrician during the third trimester. Care could be sought from an obstetrician at any time during the pregnancy, which constitutes additional medical care over and above prenatal health care.

\section{Procedure}

The self-report measures were completed in the waiting room of the prenatal clinics in conjunction with regularly scheduled appointments. All participants were assured of confidentiality, as the medical staff did not have access to the completed questionnaires. Our longitudinal design allowed us to build an hypothesized model establishing temporal relations among the factors. We assessed perceived health, perceived stress, and pregnancy adjustment at gestational week $10(M=10.34, \mathrm{SD}=1.70)$, social support and personality (negative affect and hostility) at week $12(M=12.71, \mathrm{SD}=1.57)$, symptoms at week $28(M=28.23, \mathrm{SD}=1.15)$, perceived health at week $32(M=32.33, \mathrm{SD}=$ $.95)$ and, lastly, symptoms were again assessed at week $36(M=36.17, \mathrm{SD}=.82)$.

\section{Measures}

Perceived health We used four items to measure perceived health which were rated on a 1-7 scale: (1) I perceive my health presently as (very poor to very good), (2) In comparison to other pregnant women, I feel (much worse to much better), (3) I perceive my general fitness presently as (very poor to very good), and (4) I feel that my pregnancy affects my health (very negatively to very positively). We included functional ability (3) and comparative (2) items because both have been found to be pertinent to the measure of perceived health (Bjorner et al., 1996). Internal consistency was acceptable (at week 10 , Cronbach's alpha $=.77$; at week 32 , Cronbach's alpha $=.78$ ).

Perceived Stress Scale A Swedish 11-item version (back-translated) of the Perceived Stress Scale (PSS; Cohen \& Williamson, 1988) was used to assess global perceived stress. The PSS taps the degree to which events are appraised as threatening, such as 'How often have you felt you were unable to control the important things in your life?' Each item was rated on a 5-point scale ranging from never to experienced very often, for the previous 4-week period. Internal consistency was high $($ Cronbach's alpha $=.89)$.

Pregnancy adjustment Pregnancy adjustment was assessed by 7 items rated on a 7-point scale which covered several relevant domains, including the woman's attitude towards the pregnancy, how she felt about her altered physical appearance, how she felt physically in comparison to her expectations, to what extent she felt like an important person during pregnancy, and to what extent she thought about her expected baby. Internal consistency was acceptable (Cronbach's alpha $=.67$ ).

Negative affect The Eysenck Personality Inventory-Neuroticism Scale is a commonly used measure of negative affect. We used an abbreviated form (17 items) of the Swedish standardized version (Bederoff-Petersson, Jägtoft \& Åström, 1968) of the neuroticism scale (Cronbach's alpha $=.77)$.

Hostility We administered an abbreviated version of the Cook-Medley Hostility Scale (Ho) 
taken from the MMPI (Cook \& Medley, 1954). The 17-item measure, rated on a 5-point scale (1, definitely disagree to 5, definitely agree) has been previously tested in a Swedish study (Heslyk, Rönngren, \& Semb, 1986) and found to reflect cynicism and paranoia. We found that internal consistency was acceptable (Cronbach's alpha $=$ .86) and similar to what other studies have found. Construct validity was demonstrated in the Swedish translation of the Ho scale (Öhman, Burell, Ramund, \& Fleischman, 1992).

Social support The social support measure (Crnic, Greenberg, Robinson, \& Basham, 1983; Crnic, Greenberg, \& Slough, 1986; Henderson, Byrne, \& Duncan-Jones, 1981) has previously been used in Swedish research on pregnancy (Rodriguez et al., in press) and mother-infant functioning (Lindberg, Bohlin, Hagekull, \& Thunstrom, 1994). The wording on 5 of the 10 items was adapted to focus on the pregnancy's effect on relationships, e.g. feeling more socially isolated during pregnancy and partner's degree of understanding. Items were rated on a 7-point scale and tapped emotional support and satisfaction with the support received from the expectant father and friends. Internal consistency for the entire scale was acceptable (Cronbach's alpha $=.75)$.

Symptom reports The symptom checklist (Berglund \& Lindmark, 1988) consisted of 27 pregnancy symptoms. All symptoms were coded as either present or absent. Twenty symptoms on the checklist were considered to be 'benign' because they are relatively common symptoms during pregnancy which do not necessarily indicate a specific pregnancy complication in their own right. ${ }^{1}$ Seven symptoms that may be indicative of possible complications (bleeding, severe contractions, difficulty breathing, fast/irregular pulse, vaginal itchiness, stomach ache, and urinary problems) were selected on the basis of their clinical significance by a group of experienced obstetricians. Because contradictions are 'normal' in late pregnancy, this was not considered a medically relevant symptom at week 36 . Even though they need not lead to poor maternal or neonatal outcomes, these symptoms are monitored closely and examined by medical professionals in order to rule out possible pathology.

Health/medical care utilization We collected data regarding health care utilization directly from the medical chart. Our baseline measure of health care consisted of the week in which prenatal care was initiated and the total number of visits to the prenatal health clinic during the first half of pregnancy. The two outcome measures of medical care were the number of visits to an obstetrician and emergency room during the last trimester. These two measures reflect additional medical care beyond the routine prenatal care the women received.

\section{Results}

Table 1 shows the descriptive statistics for the

Table 1. Descriptive statistics of study variables

\begin{tabular}{|c|c|c|c|}
\hline Study variables & $M$ & $S D$ & $R$ \\
\hline Perceived health (week 10) & 4.84 & 1.07 & $2-7$ \\
\hline Perceived health (week 32) & 4.78 & 1.05 & $2-7$ \\
\hline Pregnancy adjustment & 5.34 & 0.91 & $2-7$ \\
\hline Perceived stress & 2.40 & 0.63 & $1-4$ \\
\hline Social support & 5.49 & 0.77 & $2-7$ \\
\hline Negative affect & 6.01 & 3.40 & $0-17$ \\
\hline Hostility & 2.01 & 0.52 & $1-4$ \\
\hline Medical symptoms (week 28) & 2.01 & 1.48 & $0-6$ \\
\hline Medical symptoms (week 36) & 1.65 & 1.37 & $0-6$ \\
\hline Benign symptoms (week 28) & 8.42 & 4.00 & $0-20$ \\
\hline Benign symptoms (week 36) & 9.19 & 5.22 & $0-21$ \\
\hline Week of prenatal care initiation & 9.91 & 1.84 & $6-22$ \\
\hline Prenatal care utilization during first half of pregnancy & 1.89 & 0.84 & $0-7$ \\
\hline Medical care utilization & 1.50 & 1.40 & $0-13$ \\
\hline Emergency room visits & 0.33 & 0.68 & $0-5$ \\
\hline
\end{tabular}


study variables. The majority of participants had zero risk factors (52 percent), disorders (91 percent), and were not hospitalized (91 percent) prior to delivery. Gestational age ranged from 23 to 43 weeks, the mode was at 40 weeks (30 percent). Seventy-five percent of the total sample were non-smokers prior to pregnancy and 9 percent of the entire sample smoked throughout the course of pregnancy (see Rodriguez et al., in press). Only 4 percent of the sample abstained from alcoholic beverages prior to pregnancy; in contrast 77 percent abstained by week $36 .^{2}$ Figures 2 and 3 show the frequency distributions for medically relevant and benign symptoms respectively for weeks 28 and 36 . Contractions were coded as a medically relevant symptom if they were experienced during week 28 but as a benign symptom if they were experienced during week 36. Fifty-five percent of the sample reported experiencing contractions during week 28 , and 83 percent during week 36 . Table 2 shows the correlation matrix for the study variables.
LISREL 8.12 for Windows (Jöreskog \& Sörbom, 1993) is a structural equation modeling procedure that enables researchers to test several variables simultaneously in the form of an hypothesized model, which provides the opportunity to disentangle both the direct and the indirect effects. Reliability for each measure was used to calculate error variability when constructing the latent variables. We interpreted the results by examining four statistics that indicate how well the model fits the data. A model is said to fit the data well when the chi-square statistic is non-significant, the Goodness of Fit Index (GFI) which is unaffected by sample size approaches 1, the root mean square error of approximation (RMSEA) is no larger than .05 and its probability value for closeness of fit approaches 1 , and the expected cross-validation index (ECVI) is small relative to ECVI values of alternative models. The lowest ECVI indicates the most parsimonious model, i.e. a well-fitting model that uses the fewest number of paths. We tested the model as seen in Figure 1. The model

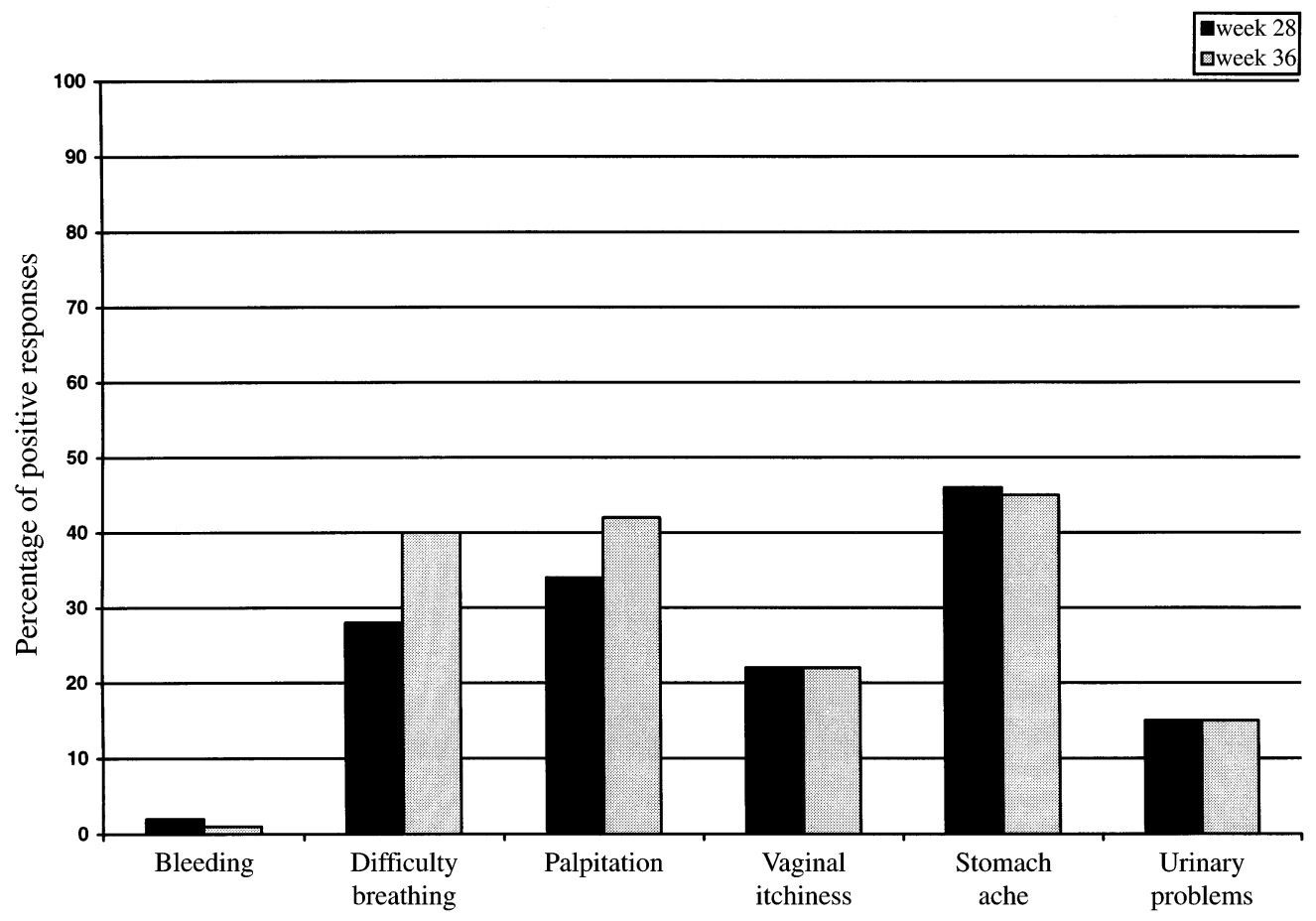

Medically relevant symptoms

Figure 2. Percentage of women experiencing medically relevant symptoms during gestational weeks 28 and 36. 
was an adequate representation of the data as indicated by several statistics, GFI $=.97$ and RMSEA $=.032, p<.97$, and the chi-square statistic, $\chi_{(\text {d.f. }=60, N=364)}^{2}=82.52, p=.03$. The ECVI equaled .56. There were a number of nonsignificant paths which were all removed at once $;^{3}$ doing so did not significantly change the model's fit, $\left(\chi_{\text {difference, d.f. }=11}^{2}=6.66, p=.83\right)$. We checked whether any paths would reach significance after all non-significant paths had been freed. A path from pregnancy adjustment to perceived health was significant and the addition of this path offered a good-fitting model, $\chi_{\text {d.f. }=70}^{2}$ $=82.36, p=.15, \mathrm{GFI}=.97$ and $\mathrm{RMSEA}=$ $.022, p<1.00$, and ECVI $=.50$. However, after adding this path, the path from perceived health at week 10 to perceived health at week 32 became non-significant. The removal of this path did not significantly change the model, $\chi_{\text {difference, d.f. }=1}^{2}=2.47, p=.13$. We inspected the model to see if any of the previously freed paths were significant and found that three paths now reached significance (perceived stress to week 28 medically relevant symptoms, hostility to week 36 medically relevant symptoms, and hostility to baseline utilization). We added these paths which resulted in further improvement $\left(\chi_{\text {difference, d.f. }=3}^{2}=16.23, p=.001\right)$. The path from perceived stress to baseline utilization became non-significant and was removed. This model represented the data very well, $\chi_{\text {d.f. }=69}^{2}=$ $70.28, p=.43$, GFI $=.97$ and RMSEA $=.007$, $p<1.00$, and ECVI $=.47$. We again tested the possibility that our original hypothesis concerning the stability of perceived health (i.e. the path from week 10 to week 32) would be supported. We removed the path from pregnancy adjustment to perceived health and replaced it with the path from perceived health at week 10 to week 32. After the removal of the path from pregnancy adjustment, the perceived health (week 10 to 32) path became significant. This alternate model, however, did not fit the data as well as the previous model, $\chi_{\text {d.f. }=69}^{2}=78.04, p=.21$ and $\mathrm{ECVI}=.50$. Therefore, it was rejected and the previous model was accepted (that included the path from pregnancy adjustment to perceived health) which fitted the data better and had the lowest ECVI value in comparison to all other models. No other paths were significant. There was no reciprocal effect of perceived health on symptoms.
The model (Figure 4) explained a considerable amount of variance in perceived health. Medically relevant symptoms and pregnancy adjustment together accounted for 48 percent of the variance in perceived health. Positive pregnancy adjustment predicted better perceived health, whereas medically relevant symptoms predicted poorer health. Medically relevant symptoms at week 28 were predicted by negative affect, social support, and perceived stress which together explained 32 percent of the variance. Medical symptoms at week 36 were predicted by hostility and medically relevant symptoms at week 28 , which together explained 73 percent of the variance. The bulk of the variance was contributed by medically relevant symptoms at week 28 . In contrast, the model was able to account for a very small portion of the variance in the benign symptoms; at week 28, 4 percent was explained solely by medically relevant symptoms. Benign symptoms were somewhat stable over time: 35 percent of the variance at week 36 was explained by week 28 benign symptoms. Baseline utilization was predicted by negative affect, hostility, pregnancy adjustment, and perceived health which together accounted for 31 percent of the variance. Third-trimester medical care utilization was accounted solely by perceived health which explained 12 percent of the variance. Emergency room visits were explained by third-trimester medical care utilization and perceived stress which together accounted for 13 percent of the variance.

Social support was the only predictor that had a significant indirect effect on benign symptoms at week 28 and on medical symptoms in the expected direction. Social support and perceived stress had significant indirect effects on perceived health.

According to Cnattingius and Nordström (1996), smoking during pregnancy has become the single most important preventable risk factor of adverse pregnancy outcomes. It is possible that smoking may be a mechanism linking psychosocial variables to symptoms and/or perceived health during pregnancy. In order to check this possibility we retested the model with the inclusion of smoking (during the course of pregnancy) as an exogenous variable. This model yielded no significant effects of smoking on the dependent variables and provided the 


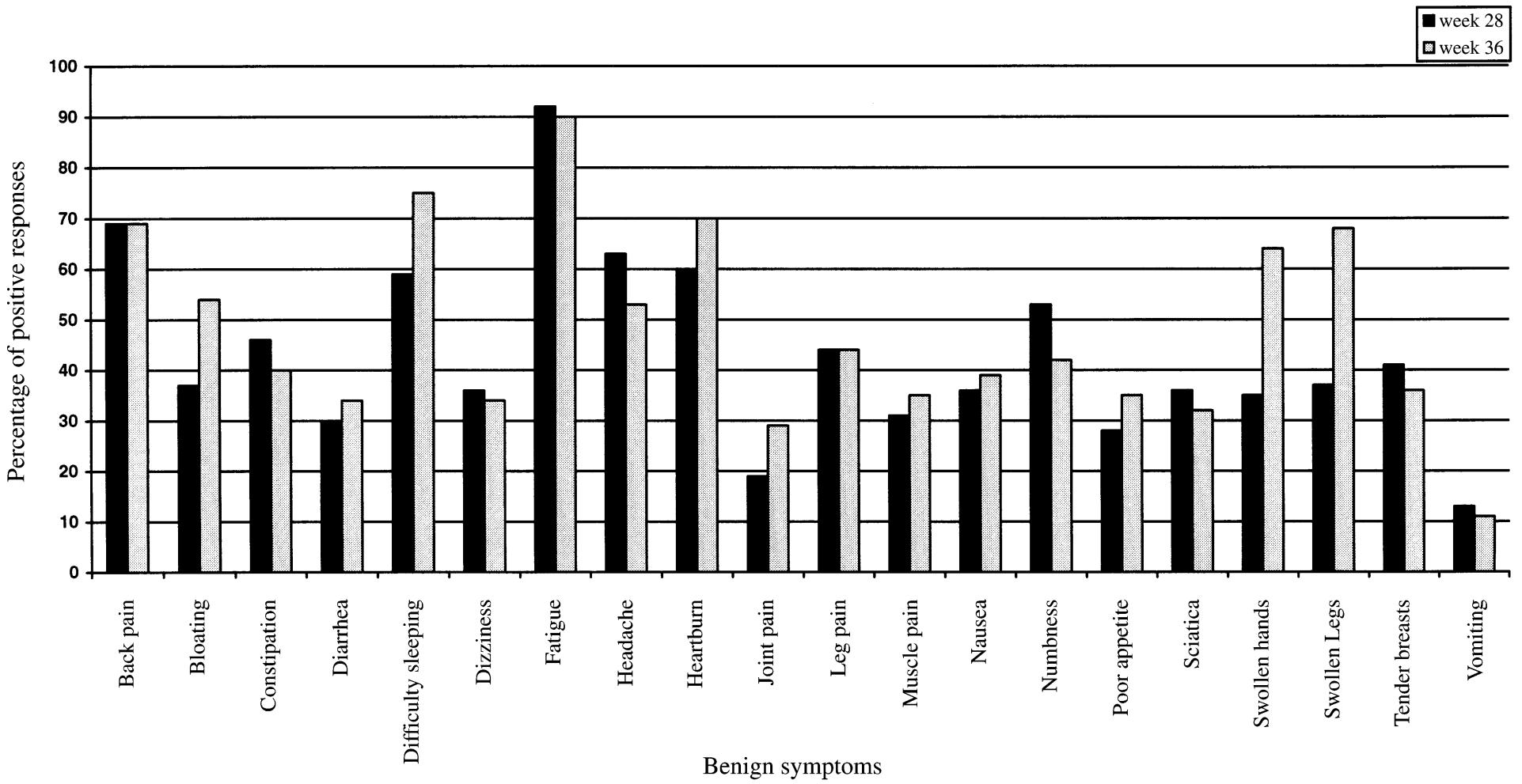

Figure 3. Percentage of women experiencing benign pregnancy symptoms during gestational weeks 28 and 36 . 
poorest fit in comparison to the models reported above $\left(\chi_{\text {d.f. }=78}^{2}=85.37, p=.27\right.$ and ECVI $=$ $.55)$.

\section{Discussion}

By building a multifactorial model that included psychosocial factors, pregnancy adjustment, and a careful differentiation of symptoms, we were able to identify the direct and indirect pathways leading to perceived health. The results of this prospective study of the antecedents of perceived health during pregnancy indicate that psychosocial factors accounted for a substantial amount of variance in symptom reports, which in turn and in conjunction with pregnancy adjustment predicted perceived health after objective measures of health were held constant. Perceived health predicted subsequent medical care utilization, which in turn and in conjunction with stress, predicted emergency room visits. Because we used a longitudinal design, the results may be discussed in terms of causal inferences.

We found that medically relevant and benign symptoms were differentially predicted. Medically relevant symptoms at week 28 were predicted by first-trimester social support, perceived stress, and negative affect as had been expected; together these variables explained a moderate amount of variance. Social support accounted for the greatest portion of this variance. Hostility had a distal effect on medically relevant symptoms, over a 24-week period. Participants who were high on hostility at week 12 were more likely to report medically relevant symptoms at week 36 . Hostility is an underrepresented variable within pregnancy studies and our findings show that it merits a place within pregnancy research. Medically relevant symptoms were very stable over time and this effect accounted for the large portion of variance that could be explained at week 36 .

No factor in our model besides concurrent medically relevant symptoms, which accounted for a very small portion of the variance, predicted benign symptoms directly. Social support predicted benign symptoms indirectly. The more supported respondents felt at the onset, the less likely they were to report benign symptoms 16 weeks later. Because benign symptoms were not related to any of the psychosocial factors included in our model, we speculate that they may be due to physical factors, such as body mass or weight gain which may be important for musculoskeletal symptoms. Similarly, Paarlberg et al. (1996) examined three benign symptoms during pregnancy and found that they were relatively independent of psychosocial factors. Benign symptoms may also be related to job characteristics. Physiological factors may play an important role, for example gastrointestinal complaints (Baron, Ramirez \& Richter, 1993) and back pain (Kristiansson, Svärdsudd, \& von Shoultz, 1996a) have been related to hormonal concentrations. Back pain has been found to begin early and be stable throughout pregnancy (Kristiansson, Svärdsudd, \& von Shoultz, 1996b). Our results are open to an array of new questions regarding the etiology of these symptoms that are a painful nuisance for many women. Furthermore, these results may help to dispel myths concerning the psychosocial origin of benign pregnancy symptoms.

Our findings show that psychosocial variables previously associated with health outcomes contributed directly to medically relevant symptoms and not to benign symptoms. Moreover, this connection could not be explained in terms of poor health habits such as smoking or alcohol consumption. Future psychophysiological research should examine the mechanisms linking psychosocial variables to symptoms. For example, research has already shown that lack of social support during pregnancy is crosssectionally associated with stress-related neuroendocrine parameters (Wadhwa, DunkelSchetter, Chicz-DeMet, Porto, \& Sandman, 1996).

Our results indicate that it is fruitful to categorize symptoms conceptually into medically relevant and benign symptoms. First, we were able to predict medically relevant symptoms from psychosocial factors previously associated with medical outcomes. This result implies that social support, perceived stress, negative affect, and hostility are possibly having an impact on health outcomes during pregnancy beyond the effect of medical risk which we controlled statistically. Each of these factors made an independent contribution. This is an important finding because known medical risk factors alone fall short of predicting many 
Table 2. Pearson correlation matrix for study variables*

\begin{tabular}{|c|c|c|c|c|c|c|c|c|c|c|c|c|c|}
\hline & 1 & 2 & 3 & 4 & 5 & 6 & 7 & 8 & 9 & 10 & 11 & 12 & 13 \\
\hline 1. Perceived stress & 1.00 & & & & & & & & & & & & \\
\hline 2. Pregnancy adjustment & -.23 & 1.00 & & & & & & & & & & & \\
\hline 3. Perceived health (week 10) & -.47 & .33 & 1.00 & & & & & & & & & & \\
\hline 4. Social support & -.40 & .40 & .26 & 1.00 & & & & & & & & & \\
\hline 5. Negative affect & .50 & -.17 & -.20 & -.35 & 1.00 & & & & & & & & \\
\hline 6. Hostility & .26 & -.15 & -.18 & -.34 & .36 & 1.00 & & & & & & & \\
\hline 7. Benign symptoms (week 28) & .30 & -.15 & -.26 & -.24 & .28 & .13 & 1.00 & & & & & & \\
\hline $\begin{array}{l}\text { 8. Medically relevant symptoms } \\
\text { (week 28) }\end{array}$ & .25 & -.13 & -.21 & -.25 & .27 & .12 & .59 & 1.00 & & & & & \\
\hline 9. Perceived health (week 32) & -.31 & .29 & .39 & .30 & -.27 & -.17 & -.45 & -.40 & 1.00 & & & & \\
\hline 10. Benign symptoms (week 36) & .18 & -.14 & -.18 & -.19 & .19 & .14 & .54 & .39 & -.27 & 1.00 & & & \\
\hline $\begin{array}{l}\text { 11. Medically relevant symptoms } \\
\text { (week 36) }\end{array}$ & .22 & -.17 & -.18 & -.29 & .25 & .17 & .52 & .57 & -.35 & .60 & 1.00 & & \\
\hline 12. Medical utilization & .04 & -.05 & -.03 & .01 & .09 & .05 & .13 & .12 & -.21 & .12 & .10 & 1.00 & \\
\hline 13. Emergency room visits & .14 & -.03 & -.08 & -.04 & .13 & .10 & -.02 & -.01 & -.11 & .08 & -.01 & .31 & 1.00 \\
\hline
\end{tabular}

* Coefficients $\geq .10$ are significant at a probability level of .05 or lower and coefficients $\geq .13$ are significant at a probability level of .01 or lower. 
adverse pregnancy outcomes (Alexander \& Keirse, 1989). Second, by conceptually categorizing symptoms, based on medical expertise rather than participants' interpretations, into medically relevant and benign symptoms, we avoid circular reasoning. It was shown that medically relevant and not benign symptoms predicted perceived health. Medical symptoms should be instrumental in predicting perceived health, because they are likely to represent an underlying health condition. It is possible that pregnant women selectively attended to medically relevant symptoms as indicators of poor health, perhaps because they were met with heightened concern by the medical staff. When medical symptoms are experienced they may lead to a perception of poor health. Benign symptoms need not have an impact on perceived health because they may be discounted by medical professionals or by the individual (Leventhal et al., 1992). Although pregnancy was a novel experience for the women in this sample, they may have obtained information regarding the seriousness of certain symptoms through their social network (e.g. mothers, relatives, friends). Further research should explore concordance between pregnant women's and medical professionals' view on the medical relevancy of certain symptoms.

Although perceived health was significantly correlated over time, week 10 explained only a relatively small portion of the variance at week 32. According to our model the variance that perceived health at week 10 explained overlapped with the variance explained by pregnancy adjustment. This result suggests that when faced with a novel health event contextual factors may play a more prominent role in predicting subsequent perceived health than perceived health at the onset. By using LISREL, we were able to disentangle the unique effects of each variable, which might have otherwise been misinterpreted. How women perceive their health during pregnancy may be singled out from how they normally view their health when not pregnant. Pregnancy is probably considered to be a special circumstance and certainly not an illness.

Pregnancy adjustment at the onset of the study had a positive effect on perceived health 22 weeks later. Possible mechanisms linking pregnancy adjustment to perceived health may include positive mood which has been experimentally associated to feelings of positive health (Croyle \& Uretsky, 1987; Salovey \& Birnbaum, 1989). Pregnancy adjustment at mid-pregnancy has been linked to social support and to having a planned pregnancy (Rodriguez et al., in press): it is plausible that such women are in a positive mood. Negative mood, on the other hand, is said to be a consistent predictor of symptom reports (Leventhal et al., 1996). Positive pregnancy adjustment indicates that women focus their attention on their expected baby. Attentional focus is important for symptom perception, for example focusing outward reduces the chance that a symptom is perceived (Fillingim \& Fine, 1986). Pregnancy adjustment may shift women's focus from themselves to their fetuses and so they may attribute any discomfort to the pregnancy rather than as a sign of poor health. In sum, our results emphasize the need to include contextual factors surrounding a particular health event. There is little research concerning pregnancy adjustment although pregnancy is an increasingly growing area of interest within health psychology.

Our longitudinal design enabled us to explore two other hypotheses that have been mentioned in the literature. First, studies on perceived health typically control for health care utilization, because it is believed that increased health care utilization may contribute to poorer perceived health. In our sample of pregnant women, baseline health care utilization did not have an effect on perceived health towards the end of pregnancy. It is plausible that initiating prenatal health care early and visiting the midwife may have been reassuring and served to deflect concerns of poor health. The second hypothesis we checked was the notion that there might be a reciprocal effect between perceived health and symptoms, i.e. that persons who perceive their health as poor may be more vigilant and consequently be more sensitive to symptoms. Our results did not support such a theory.

We found that perceived health accounted for a moderate amount of variance in the number of doctor visits during the third trimester. Our findings reveal that perceived health, not concurrent medical symptoms, directly predicted to what extent women sought additional medical care from an obstetrician. Logically one might expect 


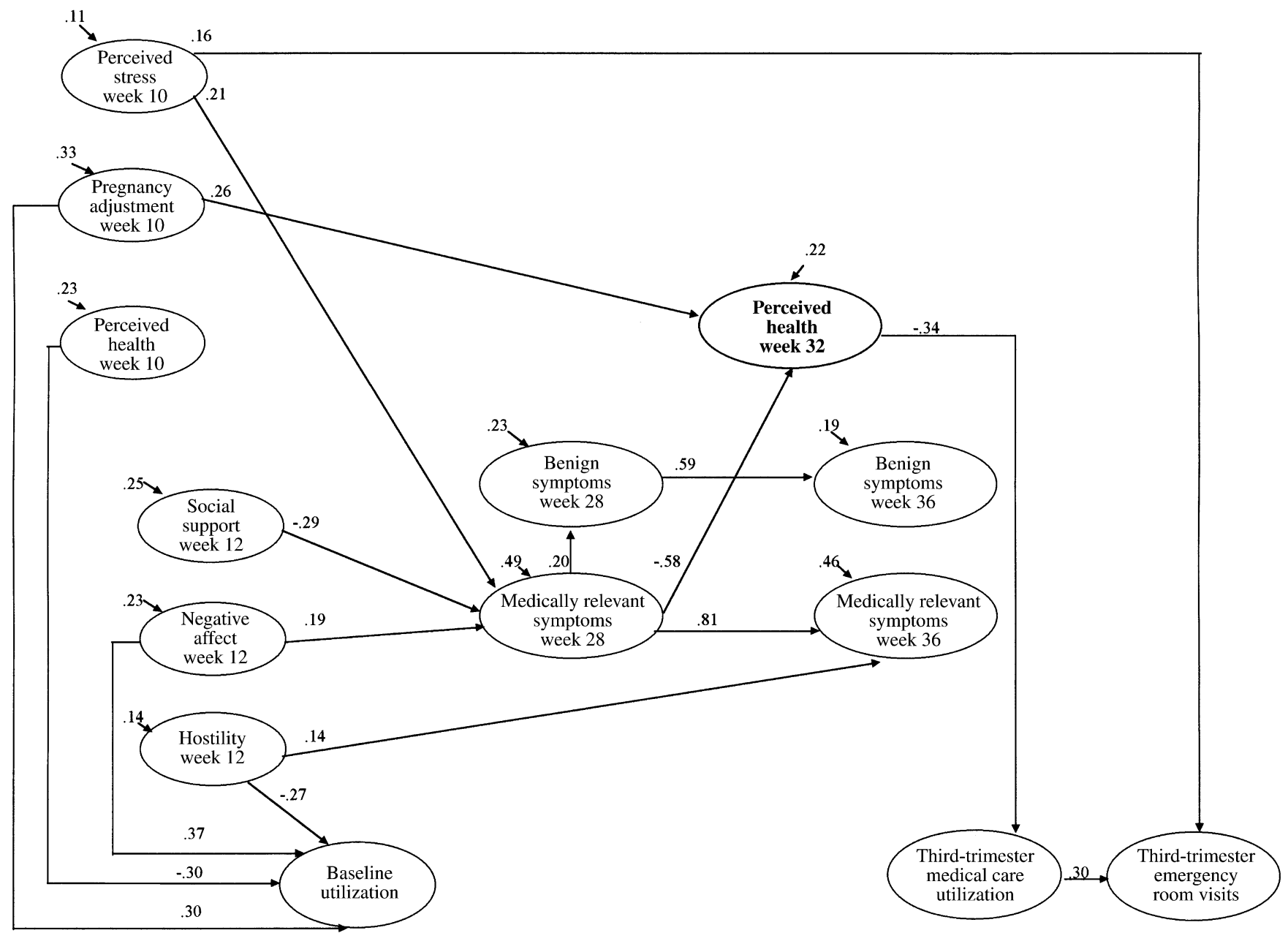

Figure 4, Structural equation model for the antecedents and consequences of perceived health $\left(\chi_{(\mathrm{d} . \mathrm{f}=69, N=364)}^{2}=70.28, p=.43\right)$. Error variances are shown outside the ovals. 
that medically relevant symptoms would prompt participants to make an appointment. Instead, medically relevant symptoms at week 28 indirectly affected utilization in the third trimester via their effect on perceived health. Symptoms alone, whether medical or benign, were not enough, rather the cognitive representation of one's health as poor was necessary. Seeking care during the third trimester was not related to baseline utilization. A possible explanation for this result may be that we studied medical care beyond routine prenatal care. Perceived health at week 10 explained baseline utilization. Because our study was conducted in Sweden, where all prenatal health care services are offered free of charge to women from all socio-economic classes, the results cannot be explained by economic or health insurance factors. Negative affect and pregnancy adjustment also contributed to the variance in baseline utilization. As a whole, these results indicate that women who are concerned about health issues and who felt that their pregnancy was important, initiated and sought prenatal care early in the pregnancy. Hostility was associated with initiating care later and consequently with fewer prenatal clinic visits during the first half of the pregnancy. Our results parallel those by Lee et al. (1992) in which they found that hostility was related to skipping medications among hypertensive men. Taken together, health care during baseline was predicted by perceived health and by contextual and personality factors; in contrast, medical care utilization during the third trimester was predicted only by perceived health.

Emergency room visits were as hypothesized predicted by the amount of concurrent doctor visits and by perceived stress. The time lag between perceived stress and emergency room visits was large (26 weeks) which is in line with Cameron et al.'s (1995) findings.

\section{Conclusions}

We have taken several steps to remedy some of the methodological limitations of previous studies concerning the antecedents of perceived health. In order to arrive at a more precise picture of perceived health, we minimized random variability in several ways, First, we addressed these issues by studying perceived health over time using a repeated measures design in a sample in which all members underwent the same health event. Second, we statistically controlled for medical risk factors as assessed via the medical record, thus eliminating the concern for confounding effects of selfreports. Third, according to Pennebaker (1982), symptom reports may be influenced by SES and ethnicity, thus we statistically controlled for SES and limited our study to Swedish women. Fourth, we controlled for variability due to parity, because symptom perceptions may be processed schematically so that multiparous women are likely to view their present symptoms and perceived health in light of their previous pregnancy and birth outcome. Future studies should test our model with populations varying in SES, ethnicity, and parity.

An important and unique aspect of this study is that we examined perceived health in light of a health event, not an illness. If we are to understand why perceived health declines and how this decline is related to later illness and mortality, then we should study the factors that influence it prior to illness. For most women, pregnancy is a normal part of the life cycle in which health concerns are focused upon and in which many biological changes take place. By studying the antecedents of perceived health and symptoms during pregnancy we shed light on the possible mechanisms that influence these factors during an illness. A parallel between pregnancy and illness may be that they both highlight the need to take contextual variables into account. We found that pregnancy adjustment moderated perceived health status, even though women who adjusted well to their pregnancies were not less likely than other women to experience symptoms. Thus the cognitive representation of one's health not only reflects psychological factors, but also encompasses contextual factors, which are of importance for one's ability to cope with a health event. The latter are particularly germane because they are potentially modifiable.

Another important methodological aspect of this study is its longitudinal design and our method of data analysis. We selected psychosocial variables from the first trimester in order to predict symptoms during the second trimester, which in turn were used to predict third-trimester perceived health. In this way we were able to unravel the direct and indirect effects among the variables as a unit, which limits the possibility 
that our findings are based on spurious associations. The results show that although our original hypotheses were supported (the original model had an acceptable fit), several paths could be eliminated. Thus variance that was explained by several variables could more accurately be represented in a frugal model. Future research is necessary to confirm our model and should include other variables that may have an impact on symptoms. The results from this investigation add to the growing body of evidence indicating that social support, negative affect, perceived stress, and hostility specifically predict medically relevant symptoms during pregnancy. Benign symptoms do not appear to be dependent of psychological factors or pregnancy adjustment as is popularly believed. In other words, psychosocial factors may have an effect on actual health outcomes and on how pregnant women perceive their health. Our results support the idea that perceived health is a cognitive representation involving biomedical and psychosocial components, with the addition of a contextual component.

\section{Notes}

1. The symptoms were back pain, bloating, constipation, diarrhea, difficulty sleeping, dizziness, fatigue, headache, heartburn, joint pain, leg pain, muscle pain, nausea, numbness, poor appetite, sciatica, swollen hands, swollen legs, tender breasts, and vomiting. Internal consistency was satisfactory (Cronbach's alpha $=.77$ for week 28 and .81 for week 36 ).

2. Smoking throughout pregnancy was marginally correlated with benign symptoms during week 36 $(r=.10, p<.05)$ but unrelated to perceived health and to medically relevant symptoms. Consuming alcoholic beverages during pregnancy was unrelated to both types of symptoms as well as to perceived health.

3. The deleted paths were: social support leading to baseline prenatal care utilization; hostility and perceived stress leading to medically relevant symptoms (week 28); negative affect, perceived stress, and pregnancy adjustment leading to benign symptoms (week 28); perceived stress and benign symptoms (week 28) leading to perceived health (week 32); baseline prenatal care utilization and medically relevant symptoms (week 36) to medical care utilization; and perceived health (week 32) to emergency room visits.

\section{References}

Åberg, A., \& Lindmark, G. (1992). Competence and compliance in antenatal care: Experience from Sweden. International Journal of Technology Assessment in Health Care, 8: Suppl. 1, 20-24.

Alexander, G. R., \& Kotelchuck, M. (1996). Quantifying the adequacy of prenatal care: A comparison of indices. Public Health Reports, 111, 408-418.

Alexander, S., \& Keirse, M. (1989). Formal risk scoring during pregnancy. In I. Chambers, M. Enkin, \& M. Keirse (Eds.), Effective care in pregnancy and childbirth (Vol. 1, pp. 345-365). Oxford: Oxford University Press.

Baron, T. H., Ramirez, B., \& Richter, J. (1993). Gastrointestinal motility disorders during pregnancy. Annals of Internal Medicine, 118 , 366-375.

Barsky, A. J., Cleary, P., \& Klerman, G. (1992). Determinants of perceived health status of medical outpatients. Social Science and Medicine, 34, $1147-1154$.

Bederoff-Petersson, Jägtoft, \& Åström (1968). Skandinaviska Testförlaget AB. Stockholm.

Berglund, A., \& Lindmark, G. (1998). Health services effects of a reduced routine programme for antenatal care: An area based study. European Journal of Obstetrics and Gynaecology and Reproductive Biology, 77, 193-199.

Bjorner, J. B., Kristensen, T., Sullivan, M., OrthGomér, K., Tibblin, G., \& Westerholm, P. (1996). Self-rated health: A useful concept in research, prevention, and clinical medicine. Stockholm: Swedish Council for Planning and Coordination of Research.

Bracken, M., Enkin, M., Campbell, H., \& Chalmers, I. (1989). Symptoms in pregnancy: nausea and vomiting, heartburn, constipation, and leg cramps. In I. Chalmers, M. Enkin, \& M. Keirse (Eds.), Effective Care in Pregnancy and Childbirth (Vol. 1, pp. 501-511). Oxford: Oxford University Press. Cameron, L., Leventhal, E., \& Leventhal, H. (1995). Seeking medical care in response to symptoms and life stress. Psychosomatic Medicine, 57, 37-47.

Chalmers, B. (1983). Psychosocial factors and obstetric complications. Psychological Medicine, 13, 333-339.

Cnattingius, S., \& Nordström, M. (1996). Maternal smoking and feto-infant mortality: biological pathways and public health significance. Acta Paediatrica, 85, 1400-1402.

Cohen, S., \& Rodriguez, M. S. (1995). Pathways linking affective disturbances and physical disorders. Health Psychology, 14, 374-380.

Cohen, S., Tyrrell, D., \& Smith, A. (1993). Negative 
life events perceived stress, negative affect, and susceptibility to the common cold. Journal of Personality and Social Psychology, 64, 131-140.

Cohen, S., \& Williamson, G. (1988). Perceived stress in a probability sample of the United States. In S. Spacapan, \& S. Oskamp (Eds.), The Social Psychology of Health: The Claremont Symposium on Applied Social Psychology (pp. 31-67). Thousand Oaks, CA: Sage.

Collins, N. L., Dunkel-Schetter, C., Lobel, M., \& Scrimshaw, S. C. M. (1993). Social support in pregnancy: Psychosocial correlates of birth outcomes and postpartum depression. Journal of Personality and Social Psychology, 65, 1243-1258.

Cook, W. W., \& Medley, D. M. (1954). Proposed hostility and pharisaic-virtue scales for the MMPI. Journal of Applied Psychology, 38, 414-418.

Crnic, K. A., Greenberg, M., Ragozin, A., Robinson, N., \& Basham, R. (1983). Effects of stress and social support on mothers and premature and fullterm infants. Child Development, 54, 209-217.

Crnic, K. A., Greenberg, M., \& Slough, N. (1986). Early stress and social support influences on mothers' and high-risk infants' functioning in late infancy. Infant Mental Health Journal, 7, 19-33.

Croyle, R., \& Uretsky, M. (1987). Effects of mood on self-appraisal of health status. Health Psychology, 6, 239-253.

De Maio-Esteves, M. (1990). Mediators of daily stress and perceived health status in adolescent girls. Nursing Research, 39, 360-364.

Diefenbach, M. A., Leventhal, E., Leventhal, H., \& Patrick-Miller, L. (1996). Negative affect relates to cross-sectional but not longitudinal symptom reporting: Data from elderly adults. Health Psychology, 15, 282-288.

Fillingim, R., \& Fine, M. (1986). The effect of internal versus external information processing on symptom perception in an exercise setting. Health Psychology, 5, 115-123.

Giblin, P., Poland, M., \& Ager, J. (1990). Effects of social supports on attitudes, health behaviors and obtaining prenatal care. Journal of Community Health, 15, 357-368.

Gold, M., Franks, P., \& Erickson, P. (1996). Assessing the health of the nation. The predictive validity of a preference-based measure and selfrated health. Medical Care, 34, 163-177.

Goodwin, J. W., Dunne, J., \& Thomas, B. (1969). Antepartum identification of the fetus at risk. Canadian Medical Association Journal, 101, 57-67.

Gudmundsson, S., Bjorgvinsdottir, L., Molin, J., Gunnarsson, G., \& Marsal, K. (1997). Socioeconimic status and perinatal outcome according to residence area in the city of Malmö.
Acta Obstetrica et Gynecologica Scandinavica, 76, 318-323.

Heidrich, S. M., Forsthoff, C., \& Ward, S. (1994). Psychological adjustment in adults with cancer: The self as a mediator. Health Psychology, 13, 346-353.

Henderson, S., Byrne, D., \& Duncan-Jones, P. (1981). Neuroses in the social environment. New York: Academic Press.

Heslyk, H., Rönngren, B., \& Semb, G. (1986). Dimensions in type A behavior (Dimensioner i Typ A beteende) (Unpublished manuscript). Department of Clinical Psychology, Uppsala University.

Hogberg, U., Innala, E., \& Sandström, A. (1994). Maternal mortality in Sweden, 1980-1988. Obstetrics and Gynecology, 84, 240-244.

Hunter, D. (1989). Diabetes in pregnancy. In I. Chalmers, M. Enkin, \& M. Keirse (Eds.), Effective care in pregnancy and childbirth (Vol. 1, pp. 578-593). Oxford: Oxford University Press.

Idler, E., \& Benyamini, Y. (1997). Self-rated health and mortality: A review of twenty-seven community studies. Journal of Health and Social Behavior, 38, 21-37.

Idler, E., \& Kasl, S. (1991). Health perceptions and survival: Do global evaluations of health status really predict mortality? Journal of Gerontology: Social Sciences, 46, S55-S65.

Jörkeskog, K., \& Sörbom, D. (1993). LISREL 8: Structural equation modeling with the simplis command language. Hillsdale, NJ: Lawrance Erlbaum Associates.

Kaplan, G., \& Camacho, T. (1983). Perceived health and mortality: a nine-year follow-up of the human population laboratory cohort. American Journal of Epidemiology, 117, 292-304.

Kristiansson, P., Svärdsudd, K., \& von Shoultz, B. (1996a). Back pain during pregnancy: A prospective study. Spine, 21, 702-709.

Kristiansson, P., Svärdsudd, K., \& von Shoultz, B. (1996b). Serum relaxin, symphyseal pain and back pain during pregnancy. American Journal of Obstetrics and Gynecology, 175, 1342-1347.

Larsen, R. J., (1992). Neuroticism and selective encoding and recall of symptoms: Evidence from a combined concurrent-retrospective study. Journal of Personality and Social Psychology, 62, 480-488.

Lederman, R. P. (1995). Relationship of anxiety, stress, and psychosocial development to reproductive health. Behavioral Medicine, 21, 101-112.

Lee, D., Mendes de Leon, C., Jenkins, C., Croog, S., Levine, S., \& Sudilovsky, A. (1992). Relation of hostility to medication adherence, symptom complaints, and blood pressure reduction in a 
clinical field trial of antihypertensive medication.

Journal of Psychosomatic Research, 36, 181-190.

Leventhal, E. A., Hansell, S., Diefenbach, M., Leventhal, H., \& Glass, D. (1996). Negative affect and self-report of physical symptoms: Two longitudinal studies of older adults. Health Psychology, 15, 193-199.

Leventhal, H., Diefenbach, M., \& Leventhal, E. (1992). Illness cognition: using common sense to understand treatment adherence and affect cognition interactions. Cognitive Therapy and Research, 16, 143-163.

Lindberg, L., Bohlin, G., Hagekull, B., \& Thunstrom, M. (1994). Early food refusal: Infant and family characteristics. Infant Mental Health Journal, 15, 262-277.

Lukacs, B., Leplege, A., Thibault, T., \& Jardin, A. (1996). Prospective study of men with clinical benign prostatic hyperplasia treated with alfuzosin by general practitioners: 1 year results. Urology, 48, 731-740.

Maddox, G. L., \& Douglas, E. B. (1973). Selfassessment of health: a longitudinal study of elderly subjects. Journal of Health and Social Behavior, 14, 87-93.

Markides, K. S., \& Lee, D. J. (1990). Predictors of well-being and functioning in older MexicanAmericans and Anglos: An eight-year follow-up. Journal of Gerontology, 45, 69-73.

Miller, T. Q., Markides, K., Chiriboga, D., \& Ray, L. (1995). A test of the psychosocial vulnerability and health behavior models of hostility: Results from an 11-year follow-up study of Mexican Americans. Psychosomatic Medicine, 57, 572-581.

Miller, T. Q., Smith, T., Turner, C., Guijarro, M., \& Hallet, A. (1996). A meta-analytic review of research on hostility and physical health. Psychological Bulletin, 119, 322-348.

Moller, L., Kristensen, T., \& Hollnagel, H. (1996). Self-rated health as a predictor of coronary heart disease. Journal of Epidemiology and Community Health, 50, 423-428.

Mossey, J., \& Shapiro, E. (1982). Self-rated health: A predictor of mortality among the elderly. American Journal of Public Health, 72, 800-808.

Nicholl, J., Brazier, J., Milner, P., Westlake, L., Kohler, B., Williams, B., Ross, B., Frost, E., \& Johnson, A. (1992). Randomized controlled trial of cost-effectiveness of lithotripsy and open cholecystectomy as treatments for gallbladder stones. Lancet, 340, 801-807.

Oakley, A., Hickey, D., Rajan, L., \& Rigby, A. (1996). Social support in pregnancy: does it have long-term effects? Journal of Reproductive and Infant Psychology, 14, 7-22.

Öhman, A., Burell, G., Ramund, B., \& Fleischman, N. (1992). Decomposing coronary-prone behavior:
Dimensions of type A behavior in the videotaped structured interview. Journal of Psychopathology and Behavioral Assessment, 14, 21-54.

Omer, H., Elizur, Y., Barnea, T., Friedlander, D., \& Palti, Z. (1986). Psychological variables and premature labour: A possible solution for some methodological problems. Journal of Psychosomatic Research, 30, 559-565.

Paarlberg, K., Vingerhoets, A., Passchier, J., Dekker, G., \& Van Geijn, H. (1995). Psychosocial factors and pregnancy outcome: A review with emphasis on methodological issues. Journal of Psychosomatic Research, 39, 563-595.

Paarlberg, K., Vingerhoets, A., Passchier, J., Heinen, A., Dekker, G., \& van Geijn, H. (1996). Psychosocial factors as predictors of maternal well-being and pregnancy-related complaints. Journal of Psychosomatic Obstetrics and Gynecology, 17, 93-102.

Pennebaker, J. W. (1982). The psychology of physical symptoms. New York: Springer-Verlag.

Puffer, R. (1993). Family planning issues relating to maternal and infant mortality in the United States. Bulletin of the Pan American Health Organization, 27, 120-134.

Radanov, B., Schwarz, H., \& Frost, S.-A. (1997). Determination of future health status expectation in rheumatoid arthritis. Journal of Psychosomatic Research, 42, 403-406.

Rodin, J., \& McAvay, G. (1992). Determinants of change in perceived health in a longitudinal study of older adults. Journal of Gerontology, Psychological Sciences, 47, P373-P384.

Rodriguez, A., \& Bohlin, G. (1998). Psychosocial factors, health behaviors, and health outcomes: Stability and change throughout pregnancy. Unpublished manuscript, Uppsala University.

Rodriguez, A., Bohlin, G., \& Lindmark, G. (in press). Psychosocial predictors of smoking and exercise during pregnancy. Journal of Reproductive and Infant Psychology.

Rodriguez, A., Lindmark, G., \& Bohlin, G. (1998). A comparison between self-reports and the medical charts of pregnant women. Manuscript submitted for publication, Uppsala University.

Salovey, P., \& Birnbaum, D. (1989). Influence of mood on health-relevant cognitions. Journal of Personality and Social Psychology, 57, 539-551.

Shumaker, S. A., \& Hill, D. R. (1991). Gender differences in social support and physical health. Health Psychology, 10, 102-111.

Stewart, D. E. (1996). Women's health and psychosomatic medicine. Journal of Psychosomatic Research, 40, 221-226.

Taylor, S. E. (1990). Health Psychology: The science and the field. American Psychologist, 45, 40-50.

Taylor, S. E., Repetti, R., \& Seeman, T. (1997). 
Health Psychology: What is an unhealthy environment and how does it get under the skin? Annual Review of Psychology, 48, 411-447.

Tessler, R., \& Mechanic, D. (1978). Psychological distress and perceived health status. Journal of Health and Social Behavior, 19, 254-262.

Van Eck, M., Berkhof, H., Nicolson, N., \& Sulon, J. (1996). The effects of perceived stress, traits, mood states, and stressful daily events on salivary cortisol. Psychosomatic Medicine, 58, 447-458.

Wadhwa, P. D., Sandman, C., Porto, M., DunkelSchetter, C., \& Garite, T. (1993). The association between prenatal stress and infant birth weight and gestational age at birth: A prospective investigation. American Journal of Obstetrics and
Gynecology, 169, 858-865.

Wadhwa, P., Dunkel-Schetter, C., Chicz-DeMet, A., Porto, M., \& Sandman, C. (1996). Prenatal psychosocial factors and the neuroendocrine axis in human pregnancy. Psychosomatic Medicine, 58, 432-446.

Watson, D., \& Pennebaker, J. (1989). Health complaints, stress, and distress: Exploring the central role of negative affectivity. Psychological Review, 96, 234-254.

Zimmermann-Tansella, C., Bertagni, P., Siani, R., \& Micciolo, R. (1994). Marital relationships and somatic and psychological symptoms in pregnancy. Social Science and Medicine, 38, $559-564$. 